\title{
Targeting arachidonic acid-related metabolites in COVID-19 patients: potential use of drug-loaded nanoparticles
}

\author{
Sherif M. Shoieb ${ }^{1} \cdot$ Mahmoud A. El-Ghiaty $^{1} \cdot$ Ayman O. S. El-Kadi $^{1}$ (I) \\ Received: 27 August 2020 / Accepted: 23 October 2020 / Published online: 17 November 2020 \\ (C) Qatar University and Springer Nature Switzerland AG 2020
}

\begin{abstract}
In March 2020, The World Health Organization (WHO) has declared that the coronavirus disease 2019 (COVID-19) is characterized as a global pandemic. As of September 2020, infection with the severe acute respiratory syndrome coronavirus 2 (SARSCoV-2) has spread to 213 countries and territories around the world, affected more than 31.5 million people, and caused more than 970,000 deaths worldwide. Although COVID-19 is a respiratory illness that mainly targets the lungs, it is currently well established that it is a multifactorial disease that affects other extra-pulmonary systems and strongly associated with a detrimental inflammatory response. Evidence has shown that SARS-CoV-2 causes perturbation in the arachidonic acid (AA) metabolic pathways; this disruption could lead to an imbalance between the pro-inflammatory metabolites of AA including mid-chain HETEs and terminal HETE (20-HETE) and the anti-inflammatory metabolites such as EETs and subterminal HETEs. Therefore, we propose novel therapeutic strategies to modulate the level of endogenous anti-inflammatory metabolites of AA and induce the patient's endogenous resolution mechanisms that will ameliorate the virus-associated systemic inflammation and enhance the primary outcomes in COVID-19 patients. Also, we propose that using nanoencapsulation of AA and its associated metabolites will contribute to the development of safer and more efficacious treatments for the management of COVID-19.
\end{abstract}

Keywords COVID-19 · Arachidonic acid · Nanoparticles $\cdot$ SARS-CoV-2 $\cdot$ Cytochrome P450 $\cdot$ EETs $\cdot$ Subterminal HETEs

\section{Introduction}

Coronavirus disease 2019 (COVID-19) has been declared by The World Health Organization (WHO) to be the cause of a global pandemic in March 2020 [1]. As of September 2020, infection with the severe acute respiratory syndrome coronavirus 2 (SARS-CoV-2) has affected more than 31.5 million people, 23 million of whom have recovered. It also caused more than 970,000 deaths worldwide [2]. The first cohort of infections was identified in Wuhan, the capital city of Hubei province in mainland China. Patients with severe outcomes were initially diagnosed with pneumonia of unknown cause; the causative pathogen was later identified as a novel

Ayman O. S. El-Kadi

aelkadi@ualberta.ca

1 Faculty of Pharmacy \& Pharmaceutical Sciences, 2142J Katz Group-Rexall Centre for Pharmacy and Health Research, University of Alberta, Edmonton, Alberta T6G 2E1, Canada enveloped RNA member of $\beta$ coronaviruses belonging to the Coronaviridae family [3]. Members of this family are known to result in mild infections. Nevertheless, the outbreaks caused by the Middle East respiratory syndrome coronavirus (MERS-CoV) and severe acute respiratory syndrome coronavirus (SARS-CoV) had significant health outcomes in terms of severity and mortality [4].

COVID-19 is a respiratory infectious illness, the major transmission route of SARS-CoV-2 from human to human is the close contact with infected individuals through respiratory droplets [5]. Other probable routes of transmission involve aerosol and oral-fecal transmission as well as touching surfaces or objects that are contaminated with the virus and then touching mucus membranes found mainly in the mouth, nose, or eyes [6, 7]. COVID-19 has an approximate incubation period of up to 14 days starting from the time of exposure to the virus; however, the majority of patients develop symptoms in the fourth or the fifth day of infection $[8,9]$. The disease has a wide range of non-specific symptoms; some infected individuals have no or mild flu-like symptoms while others could develop life-threatening outcomes including severe 
pneumonia with acute respiratory distress syndrome (ARDS) leading to death [10].

Although COVID-19 is a respiratory illness that mainly targets the lungs; it also appears to affect other extra-pulmonary systems such as the cardiovascular, renal, gastrointestinal, immune, and nervous systems [11]. The progression pace of the disease is vastly influenced by the existence of multiple patient comorbidities. Not all COVID-19 patients respond in the same manner to the virus. Elderly patients and those with numerous comorbidities such as cardiovascular disease, metabolic syndrome, cancer, renal, or immunosuppressive diseases are at a greater risk of contracting the virus and developing more severe outcomes to the infection $[12,13]$. Some countries have implemented more successful measures in fighting the pandemic than others. For instance, South Korea, Hong Kong, and Taiwan curbed community transmission of the virus earlier than other countries such as Italy, France, Spain, and the USA. These measures include rapid expansion of the PCR testing capacity, quarantine of suspected cases, mass masking strategy, early suspension of non-essential travel, and social distancing [14].

Cytochrome P450 (CYP) enzymes are a superfamily of enzymes that are involved in the metabolism of endobiotics such as steroids, arachidonic acid (AA), and bile acids as well as xenobiotics including drugs and carcinogens. The family comprises 57 human CYP enzymes that are responsible for the metabolism of approximately three-fourths of marketed drugs $[15,16]$. AA, a part of the membrane phospholipid pool, is engaged in several pathways of metabolism and most of its generated metabolites have a specific biological activity [17] AA is metabolized by CYP enzymes through three distinct metabolic pathways; the first one is allylic oxidation to generate midchain hydroxyeicosatetraenoic acids (HETEs), and the second pathway is olefinic epoxidation, by CYP epxygenases, to produce epoxyeicosatrienoic acids (EETs) typified as 5,6-, 8,9-, 11,12-, and 14,15-EET. The third group of metabolites is generated through terminal/subterminal hydroxylation reaction to form terminal 20-HETE and subterminal HETEs (Fig. 1) [18-20].

At the time of EET discovery, they were initially characterized as vascular endothelium-derived hyperpolarizing factors (EDHFs) that mainly affect the cardiovascular and renal physiology through strong vasodilatory action [21, 22]. Nevertheless, the biosynthesis of EETs is not exclusively limited to the endothelial tissue; EETs could be produced in any type of cells that express CYP epoxygenases [23]. The pharmacokinetic profile of EETs indicates that these endogenously biosynthesized compounds have short half-lives due to rapid hydrolysis by the catalytic action of soluble epoxide hydrolase $(\mathrm{sEH})$ enzymes. These are a group of enzymes found in the cytosol and peroxisomes, they specifically bind to certain epoxides and transform them into the less active corresponding diols dihydroxyeicosatrienoic acids (DHETs) [24, 25].
Strategies to enhance the biological activity of EETs include chemical inhibition of sEH and genetic techniques to knock out the expression of sEH gene, leading to stabilization of the levels of EETs and improvement of their pharmacokinetic instability [26, 27].

Another group of AA metabolites is the subterminal HETEs, they are lipid mediators that are biosynthesized by the catalytic action of CYP monooxygenases such as CYP1A1, CYP2E1, and CYP4F2 [16]. This group of metabolites comprises four members namely 16-, 17-, 18- and 19HETE; their physiological and pathophysiological roles are not fully elucidated to date. However, some of them have shown significant anti-inflammatory effects. Interestingly, their biological activity tends to be more significant in some body systems, such as the renal and cardiovascular systems $[18,28]$. Strategies to boost the level of subterminal HETEs include enzyme induction such as using isoniazid, a wellknown CYP2E1 inducer, to increase the level of 19-HETE and using synthetic analogs such as 19-HETE and 16-HETE lab-generated analogs that have longer half-lives and a better pharmacokinetic profile than the endogenously produced subterminal HETEs [29-31].

In the meantime, there is no FDA-approved drug that improves the primary outcomes such as hospitalization and mortality rates in COVID-19 patients. Interestingly, several active clinical trials are being conducted for different possible treatments for COVID-19 such as lopinavir-ritonavir, low-dose corticosteroids, favipiravir, and remdesivir. The most recent update from the RECOVERY trial, which included more than 6400 patients in the UK, shows that the cheap and widely available dexamethasone was able to decrease mortality rate by one-third among patients severely ill with COVID-19 [32, 33]. However, some patients especially those who are hypertensive, diabetic, or immunocompromised may experience serious side effects upon administration of this drug. This highlights the role that AA metabolites can play in the case of COVID-19 patients who cannot tolerate the use of glucocorticoids. Moreover, there are no clinically approved prophylactic agents for the disease [34]. Due to the seriousness and the huge impact of the pandemic, there is an increasing interest in repositioning of current clinically approved drugs and finding novel therapeutic modalities that can enhance the primary clinical outcome in COVID-19 patients.

\section{Statement of the hypothesis}

We hypothesize that infection with SARS-CoV-2 causes perturbation in the AA metabolic pathways leading to an imbalance between the pro-inflammatory metabolites of AA and its anti-inflammatory metabolites such as EETs and subterminal HETEs. In this regard, augmentation of COVID-19 patients' active resolution processes against inflammation induced by 
Terminal/subterminal HETEs

(Pro-inflammatory/Anti-inflammatory)

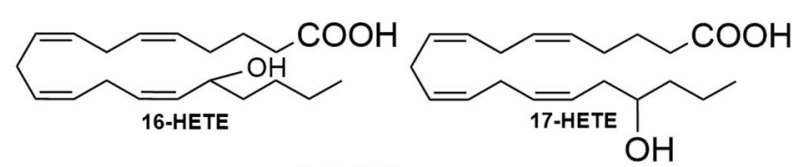

$\underbrace{\text { COOH }}_{18 \text {-HETE }}$

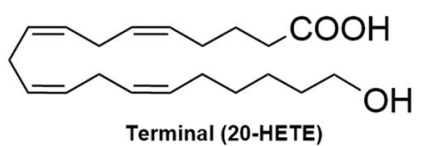

Mid-chain HETEs

(Pro-inflammatory)

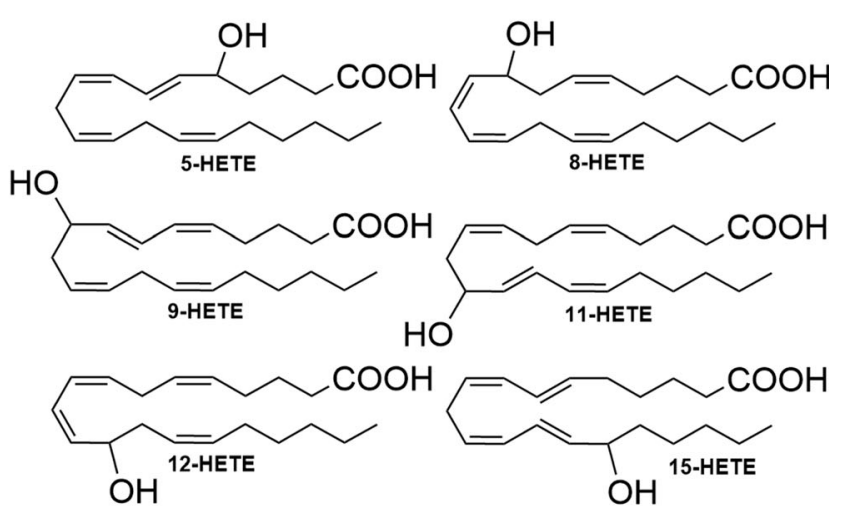

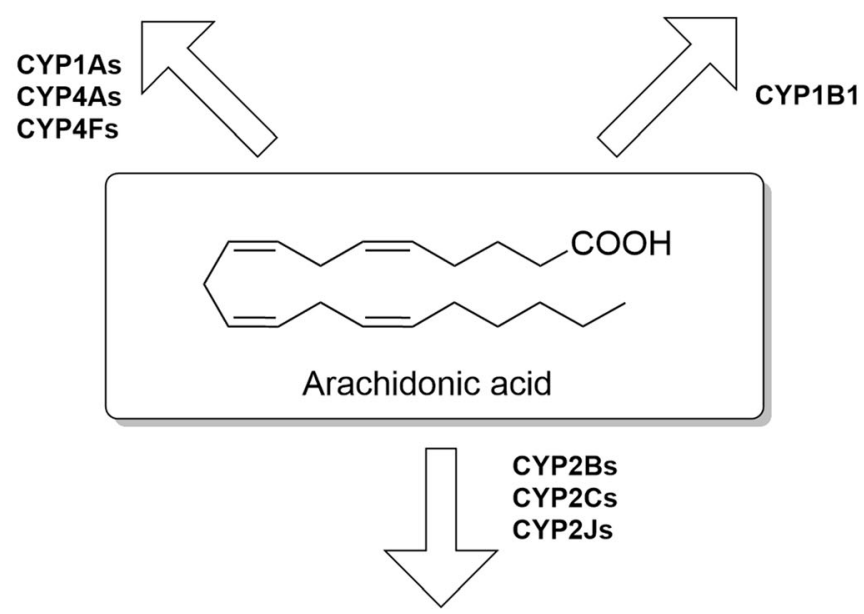

EETs

(Anti-inflammatory)

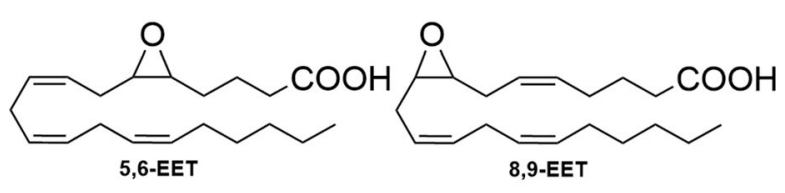

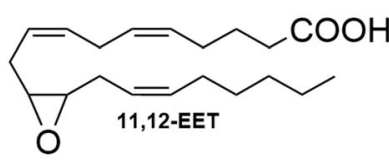

Fig. 1 Different pathways involved in cytochrome P450-mediated arachidonic acid metabolism. Arachidonic acid undergoes metabolism by

SARS-CoV-2 infection would be a perfect supplement to the current anti-inflammatory therapeutic approaches. Here, we propose novel strategies to balance the level of endogenous anti-inflammatory metabolites of AA and induce the patient's endogenous resolution mechanisms. Also, we propose that using nanoencapsulation of AA and its associated metabolites will contribute to the development of safer and more efficacious treatments for the management of COVID-19.

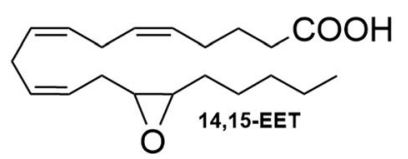

different P450 families into mid-chain HETEs, terminal/subterminal HETEs, and EETs

\section{Supporting evidence for the hypothesis}

\subsection{Coronavirus-associated perturbation in the arachidonic acid metabolic fate}

Coronaviruses are a group of enveloped viruses characterized by possessing a large single-stranded RNA. Currently, they comprise a total of seven coronaviruses that have the ability to 
infect humans, including the most recently emerging virus SARS-CoV-2 [5, 35, 36]. The SARS-CoV-2 life cycle involves lipids at different levels, ranging from serving as entry co-factors for the virus at the cell surface, representing an essential component in the process of viral replication, to the important role as an energy source that could be utilized to aid in the viral replication process [37-39]. Additionally, lipids contribute to the distribution of viral proteins, the maturation of virus particles, and the adhesion and release of the virions [40]. Therefore, the biosynthetic pathways of the host lipids represent a major determinant of the viral virulence as well as infectivity and it plays a vital role in the host defense mechanisms.

AA is a polyunsaturated fatty acid that is formed by the action of the phospholipase-A2 (PLA2) enzyme on the cell membrane phospholipids in the case of inflammatory conditions [41]. It has been suggested that AA and some of its metabolites could exert antiviral action and may be involved in the inactivation of enveloped viruses, such as influenza virus, MERS-CoV, or SARS-CoV-2. Additionally, the perturbation in AA and its associated metabolites may serve as a contributing factor that increases the susceptibility of humans to infection with these viruses [42]. Antimicrobial effects of AA have been previously reported as it has the ability to cause leakage in cell membranes or lead to uncoupling of the oxidative phosphorylation in some microorganisms [43].

SARS-CoV-2 infection causes an excessively widespread immune response in the body, a condition known as a cytokine storm. It is considered as one of the main causes of ARDS, multiple-organ failure, and even death in a brief period of time [44]. A cytokine storm causes a significant release of a number of inflammatory mediators including pro-inflammatory cytokines such as interleukin 6 (IL-6), IL-1 $\beta$, tumor necrosis factor- $\alpha$ (TNF- $\alpha)$, and eicosanoids such as AA and its associated metabolites [45].

It has been suggested that infection with SARS-CoV-2 will stimulate the immune system components such as T cells, B cells, leukocytes, and macrophages to release AA to aid in the process of inactivation of the invading pathogen. Yan et al. have performed an experiment on human coronavirus $229 \mathrm{E}$ (HCoV-229E) as a model of coronavirus infection. They infected the hepatocyte-derived carcinoma cell line (Huh-7) with the virus and analyzed the virus-mediated host cell lipid response using ultra-high-performance liquid chromatography-mass spectrometry (UPLC-MS). In this study, they showed that infection with the virus caused significant perturbation of fatty acids downstream of cytosolic PLA2 activation including AA. The results suggested that infection with coronaviruses did not disturb the composition of the cellular lipid components in a random way. Conversely, the virus modulates the infected host lipidomic and metabolomic profiles in a very accurate way to reach a sophisticated environment that is suitable and optimal for the viral invasion [45]. As an integral part of the perturbation in AA and its metabolic fate, we speculate that infection with SARS-CoV-2 will lead to an imbalance between the pro-inflammatory metabolites of AA including mid-chain HETEs and terminal HETE (20HETE) and the anti-inflammatory ones such as EETs and subterminal HETEs.

\subsection{The potential role of arachidonic acid-derived epoxyeicosatrienoic acids in the resolution of the hyperinflammatory state in COVID-19 patients}

EETs are a group of metabolites that are generated from arachidonic acid by CYP epoxygenases such as CYP2J2, CYP2C8, and CYP2C9 in different types of cells in the human body [46]. As mentioned earlier, they exert their action through hyperpolarization and subsequent relaxation of vascular smooth muscle cells by enhancing the activity of calcium-sensitive potassium $\left(\mathrm{K}_{\mathrm{Ca}}\right)$ channels $[21,47]$. EETs' biological actions are not limited to the vasodilatory effects; they have been reported to be involved in the process of resolution of inflammation in the human body. EETs have been reported to possess a non-vasodilatory property which is distinguished from their membrane-hyperpolarizing effect. EETs have the ability to inhibit NF-KB suggesting that they could be beneficial for treating vascular and nonvascular inflammatory disorders [48]. They act as special mediators that aid in promoting the removal of cellular debris and triggering the anti-inflammatory programs to prohibit multiple major pro-inflammatory cytokines [49].

Some observational studies have reported that severe cases of COVID-19 infections are closely associated with older age and whether the affected person has comorbidities such as hypertension or diabetes mellitus. However, it is obvious now that severe disease and even death could also happen in youthful patients who are otherwise healthy and have no preexisting medical conditions $[50,51]$. COVID-19 severity and mortality have been associated with elevated levels of inflammatory markers in plasma such as C-reactive protein and ferritin as well as the fibrin degradation product, D-dimers [52]. Additionally, COVID-19 patients with severe outcomes have shown a high neutrophil-to-lymphocyte ratio and elevated pro-inflammatory cytokines and chemokines that resemble other cases that involve cytokine storm [53]. In addition to the high levels of IL-6, IL-7, and TNF- $\alpha$, severe cases of COVID-19 patients have elevated production of inflammatory chemokines such as CC-chemokine ligand 2 (CCL2), CCL3, and CXC-chemokine ligand 10 (CXCL10) [54, 55].

The hyperinflammatory status is widely accepted as an essential component of severe SARS-CoV-2 infection [56]. Therefore, a comprehensive understanding of the human body measures for proper control of the heightened inflammatory state is encouraged for better treatment modalities. Lipid mediators including AA and its associated metabolites are crucial 
players in the initiation of the inflammatory response in addition to their role in the process of resolution $[57,58]$. The resolution of inflammation has been previously considered as a passive process. Nevertheless, current research has characterized the resolution of inflammation as an active and greatly sophisticated cellular and biochemical process [59, 60]. Currently, multiple endogenous bioactive lipid molecules are described to act as specialized pro-resolving mediators (SPMs) including resolvins, lipoxins, and protectins, they are highly responsible for operating the controlled resolution process that will lead eventually to the cessation of the inflammatory status [61-64].

Other key lipid mediators that participate in the effective resolution of inflammation include the AA-derived EETs. Along with other epoxy fatty acids, EETs stimulate the formation of SPMs through redirecting the metabolic pathways of AA to enhance the process of resolution of inflammation $[65,66]$. Analysis of bronchoalveolar fluid obtained from severe COVID-19 patients has demonstrated that it has high levels of CCL2 and CCL7 chemokines. Both are strong recruiters of CC-chemokine receptor 2-positive (CCR2+) monocytes, a key component of the hyperinflammatory state $[67,68]$. It has been shown that human monocytes express CYP epoxygenases such CYP2J and CYP2C enzymes. CYP2J2 and EETs have been previously demonstrated to possess strong anti-inflammatory effects through inhibition of nuclear factor-kappa B (NF-kB) [69]. Additionally, mice treated with epoxygenase inhibitor (SKF525A) have shown a significant decrease in arachidonic acid-derived EETs and resulted in a dramatic increase in the recruitment of monocytes. On the other hand, $\mathrm{sEH}^{-/-}$mice showed completely opposite phenotype to epoxygenase-inhibited mice in the course of inflammation resolution. Epoxygenase inhibition has led to recruitment of CCR2+ and CCL2 ${ }^{\text {hi }}$ monocytes in addition to substantial levels of CCL2 peptide [49].

It is well established that EETs are swiftly hydrolyzed by the sEH enzyme. For this reason, using sEH inhibitors is representing a successful strategy to stabilize EET levels. Another strategy to boost the level of EETs is to use epoxygenase product mimetics (EETs synthetic analogs) [70-72]. While most of the ongoing clinical trials on COVID-19 patients are examining either antiviral or anti-inflammatory agents in order to treat the disease, potentiation of the endogenous inflammation resolution pathways represents a novel therapeutic modality for the treatment of COVID-19 [73-75]. Interestingly, several reports have shown that EETs, CYP epoxygenases, and sEH are also widely spread in both central and peripheral nervous systems. EETs have evident neuroprotective effects on the central nervous system, they modulate the neuronal excitability, increase the cerebral blood flow, and, most importantly, reduce neuroinflammation [76-78]. Given the complexity of the hyperinflammatory status in COVID-19 patients as well as virus-induced acute disseminated encephalomyelitis, it is now widely accepted that targeting a single pro-inflammatory mediator might not be sufficient to attenuate COVID-19 progression [79, 80]. Therefore, we postulate that using sEH inhibitors or EETs synthetic analogs could offer new therapeutic interventions that aid in the management of COVID-19.

\subsection{Could the modulation of subterminal hydroxyeicosatetraenoic acid levels be effective for the treatment of COVID-19?}

Subterminal ( $\omega$-n)-hydroxylation is described as an oxidation reaction mediated by CYP monooxygenases enzymes that transform the methylene (-CH2-) group number 16 to 19 found in the hydrophobic long chain of AA into more polar alcohol products known as subterminal hydroxyeicosatetraenoic acids (HETEs) [16, 81]. Subterminal HETEs comprise a group of bioactive lipid mediators that are involved in a wide array of physiological and pathophysiological processes [82]. They are endogenously formed through the metabolic action of some CYP enzymes including CYP1A1 which transform AA into different metabolites namely 19-HETE $>18$-HETE $>17$-HETE $=16$-HETE. In addition, human CYP1A2, CYP2C19, CYP2E1, CYP4A11, and CYP4F2 have been also reported to be involved in the formation of subterminal HETEs especially 16- and 19-HETE [83-87].

A considerable number of patients infected with SARSCoV-2 develop ARDS that is significantly associated with a very high mortality rate. One prominent characteristic of the ARDS is the recruitment of neutrophils into the extravascular compartments of the lungs [52, 88-90]. The process of neutrophil migration involves neutrophil priming leading to decreased deformability and confinement within the pulmonary capillary bed. Then, neutrophils migrate through endothelium reaching the airspaces, where they get transformed into phagocytes that attack the virus by releasing oxidants and proteases [91, 92]. In human blood, neutrophils represent the predominant phagocytic cell type, comprising nearly 50-60\% of all leukocytes [93]. Neutrophils as well as their toxic metabolites represent the major cause of tissue injury in the case of ARDS. They are responsible for the elevated lung epithelial and endothelial permeability that eventually lead to alveolar edema and arterial hypoxemia. Indeed, ARDS-associated death is strongly correlated with the degree of neutrophilia in the lung [94-96].

Incubation of human polymorphonuclear neutrophils (PMNs) with a sub-stimulatory concentration of AA led to the formation of 16-HETE which is believed to be involved in the unstimulated status of the neutrophils. 16-HETE has been reported to act as a natural inhibitor of PMNs through hormone-like reaction. The mechanism of inhibition is through deactivation of recruitment, aggregation, and 
adhesion of PMNs. Additionally, esterified 16-HETE has a potent effect on the affinity of PMNs adhesion receptors towards endothelial cells since it alters the composition and physical characteristics of the cell membrane of PMNs [97, 98]. Moreover, 16-HETE has been demonstrated to act as a potent and specific inhibitor of PMNs function in vitro and has been capable of decreasing elevated intracranial pressure in an experimental model of thromboembolic stroke. Consequently, the anti-neutrophil effect of 16-HETE could be considered as a novel anti-inflammatory approach in the case of COVID-19 patients where neutrophil activation represents a major cause of tissue injury $[99,100]$.

Another member of subterminal HETEs is 19-HETE; it has been also reported to possess anti-inflammatory effects. It is protected against angiotensin II-induced cellular hypertrophy by reducing the level of pro-inflammatory midchain HETEs. Also, it noncompetitively inhibited the catalytic activity of CYP1B1, decreased the levels of lipoxygenase and cyclooxygenase- 2 enzymes, and decreased the levels of IL- 6 and IL- 8 $[18,101]$. Strategies to enhance the levels of subterminal HETEs in the body include using specific CYP modulators such as isoniazid, a well-established inducer of hepatic CYP2E1, that increase the production of endogenous 19HETE levels as well as using subterminal HETE synthetic analogs $[29,30,102]$. Table 1 shows a number of clinically approved drugs that we suggest could be included in the ongoing search for a treatment or adjuvant treatment of COVID19 as well as their potential mechanism of action.

The clinical and experimental usage of subterminal HETE metabolites is facing a real challenge of the poor pharmacokinetic profile of these compounds. Therefore, this necessitates the need for the development of pharmacological agents that have enhanced bioavailability and possessing a metabolically stable pharmacokinetic properties. For the purpose of designing robust 19-HETE analogs, Falck et al. have used the carbon backbone of 20-hydroxyeicosa-5(Z),14(Z)-dienoic acid (20-
5,14-HEDE) for the synthesis of 19-HETE synthetic analogs after incorporation of hydroxyl group at C(19) [30]. Likewise, some 16-HETE synthetic analogs have been invented and proved to maintain the biological activity of 16-HETE but with higher stability and longer half-lives. These analogs are protected from the auto-oxidation process and metabolism by lipoxygenase and cyclooxygenase branches of the AA pathway [109].

Taken together, here, we speculate that modulating the levels of specific subterminal HETEs could serve as a potential therapeutic modality to limit the inflammatory lung injury associated with SARS-CoV-2 infection, without having a negative effect on the patient's own defense mechanisms. In addition, we also suggest that inhibition of the pro-inflammatory AA metabolites such as mid-chain HETEs and 20-HETE could be also considered as a possible target in COVID-19 patients. Illustration diagram (Fig. 2) summarizes the suggested imbalance between pro-inflammatory and anti-inflammatory AA metabolites in COVID-19 patients and modulating their levels as a potential therapeutic target.

\subsection{Promising role of drug-loaded nanoparticles in the treatment of COVID-19}

Scarce information is known about subterminal HETEs pharmacokinetic profile and their specific catabolic pathways. Nevertheless, because of the great similarity between their structures and 20-HETE, it is reasonable that they share identical catabolic pathways with this terminal HETE. For instance, they could be metabolized by $\beta$-oxidation, esterification, alcohol dehydrogenase oxidation, cyclooxygenase/ lipoxygenase metabolism, and auto-oxidation. Also, one study has shown that a large portion of the urinary excreted HETEs are conjugated to glucuronide and are of hepatic origin [110]. Therefore, this instability represents a challenging limitation against their use as a research tool and hinders their
Table 1 List of clinically approved drugs and other agents that are known as CYP modulators and suggested to be used as potential candidates in the ongoing search for effective treatment or adjuvant therapy for COVID-19

\begin{tabular}{llc}
\hline Drug & Mechanism of action & References \\
\hline Aspirin & $\begin{array}{l}\text { Low-dose aspirin (50 mg daily) has been clinically reported to induce the } \\
\text { activity of CYP2C19 in both 7-day and 14-day time course. }\end{array}$ & {$[16,142]$} \\
Fenofibrate & $\begin{array}{l}\text { Antihyperlipidimic drug that has been shown to significantly increase the } \\
\text { formation of 14,15-EET, 11,12-EET, and 8,9-EET, and decrease the }\end{array}$ & {$[143]$} \\
& formation of 20-HETE. & \\
Fluconazole & $\begin{array}{l}\text { Antifungal agent that has been shown to act as a specific inhibitor for the } \\
\text { production of the pro-inflammatory metabolites of AA (mid-chain }\end{array}$ & {$[87,144]$} \\
& HETEs). & \\
Isoniazid & $\begin{array}{l}\text { Anti-bacterial agent that is a well-known inducer of hepatic CYP2E1, it } \\
\text { has been reported to result in a consequent increase in 19-HETE for- }\end{array}$ & {$[29]$} \\
mation rate. & \\
Resveratrol & $\begin{array}{l}\text { Nutritional supplement that has been recently demonstrated to directly } \\
\text { inhibit CYP1B1 and decrease its associated mid-chain HETEs. }\end{array}$ & {$[87,145]$} \\
2-methoxyestradiol & A biologically active metabolite of estradiol that has been reported to act as & {$[146,147]$} \\
& a selective CYP1B1 inhibitor and as a strong anti-inflammatory agent. & \\
\hline
\end{tabular}




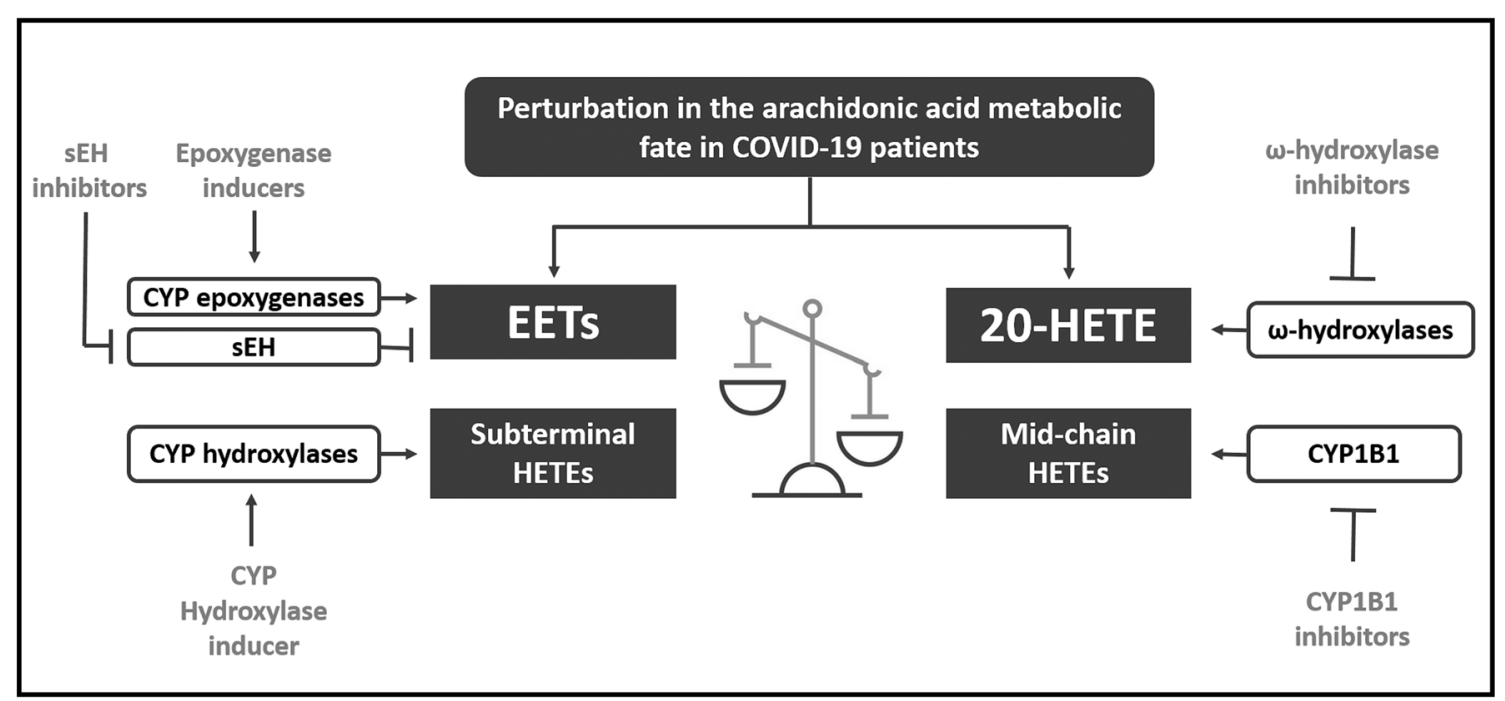

Fig. 2 Illustration diagram summarizes the perturbation in arachidonic acid metabolic fate characterizing the imbalance between proinflammatory and anti-inflammatory metabolites in COVID-19 patients

benefits in pharmacotherapy $[30,111,112]$. Consequently, the application of a drug delivery system in this case would have a significant superiority.

Currently, massive attention has been paid to nanomedicine, defined as the medical application of nanotechnology for diagnosis, prophylaxis, and treatment of diseases, as it plays an important role in hastening the development of potential clinically translatable treatments against SARSCoV-2 [113, 114]. Previously, nanomedicine has already shown its promising effectiveness against multiple viral infections such as influenza virus [115], hepatitis B virus (HBV), hepatitis C virus (HCV)[116], HIV [117], and respiratory syncytial virus [118]. COVID-19 adds a considerable global health burden to the already existing challenge represented by other viral infections; it has an unfavorable influence on both health and socioeconomic status [119]. In some diseases, effective treatment of the infection is curbed by the emergence of drug resistance that will eventually lead to increased public health burden, and elevation of morbidity and mortality rates $[120,121]$. Therefore, there is an urgent need for the development of new approaches to treat COVID-19. In this regard, the development of drug-loaded nanoparticles that encompass some molecules which are known to target AA metabolites in COVID-19 patients represents a possible therapeutic approach in the ongoing search for COVID-19 treatment.

The antiviral activity of nanoparticles is attributed to several mechanisms. Nanoparticles possess peerless physicochemical properties that enable them to act as an effective antiviral therapy including a small particle size that enhances drug delivery into anatomically challenging sites [122, 123], a large surface area that allows for accommodation of high amounts of the drug [124], and the capability to modify the surface charge in order to enhance cellular entry through the and how could modulating their levels serve as a potential therapeutic target. EETs, epoxyeicosatrienoic acids; sEH, soluble epoxide hydrolase

negatively charged cellular membrane $[125,126]$. In addition, nanoparticles possess intrinsic antiviral activity as it could be produced to have biomimetic features. A well-known example of this property is silver nanoparticles that have been shown to possess antiviral activity against HBV, HIV, and influenza virus [127, 128]. Also, gold nanoparticles have demonstrated substantial virucidal activity against the measles virus presenting them as a possible candidate for the prevention and treatment of enveloped viruses [129]. Moreover, nanoparticles provide a platform for optimization of drug dosing and augmentation of drug delivery through enhanced stability and prolonged drug retention times [130,131]. They also possess the advantage of being able to be targeted with enhanced specificity towards particular cell types, specific organs, or even cellular organelles on the molecular level [132].

On the other hand, nanoparticles cannot be assigned to the term flawless. The tiny size of nanoparticles may increase their rate of clearance from the body to an extent that could hinder their usage in drug delivery [133]. Also, once the phagocytic machinery in the liver comes in contact with some types of nanoparticles, the particles got recognized, entrapped, and instantly removed from the circulation leading to a significant challenge in their design [134]. Moreover, nanoparticles can possess cellular activities that do not exist with traditional pharmacotherapy. For instance, these particles could have the ability to reach certain cellular compartments such as the nucleus or the mitochondria and cause detrimental effects [135].

It has been suggested that some strategies could be used to target SARS-CoV-2 using nanoparticles. The virus entry to the target cell is initiated with spike (S) protein (entry protein). Entry starts with binding of the surface unit, S1, of the S protein to angiotensin-converting enzyme 2 (ACE2), hence initiating viral attachment to the outer part of target cells 
[136-138]. Therefore, nanoparticles have been previously constructed to block $\mathrm{S}$ protein and prevent coronaviral entry into cells. For instance, based on docking-mediated virtual screening, a group of peptide inhibitors for heptad repeat 1 (HR1) has been developed. HR1 and HR2 are major domains in the $\mathrm{S}$ protein of coronavirus; their inhibition will lead to the suppression of HR1/HR2-mediated membrane binding between MERS-CoV and host cells. One of the tested peptides showed promising results; it is called pregnancy-induced hypertension (PIH) peptide; it demonstrated a significant inhibitory effect possessing IC50 of $1.171 \mu \mathrm{M}$. Interestingly, the inhibitory effect of PIH has been further enhanced 10-fold by formulating the gold nanorod complex. Additionally, the nano-formula has shown improved pharmacokinetic profile and biocompatibility on both levels, in vitro and in vivo $[139,140]$.

Similarly, peptide inhibitors against SARS-CoV-2 have been designed and simulated. The inhibitors' design was extracted from the protease domain of ACE2, which associates with SARS-CoV-2 receptor binding domains. These peptides were conjugated to the surfaces of nanoparticle reservoirs to enhance the metabolic stability and effectiveness of these inhibitors [141]. Another example of nanostructures used against coronaviruses is the carbon quantum dots (CQDs); they are classified into the first generation of antiviral CQDs that are synthesized from ethylenediamine/citric acid as carbon precursors and then conjugated with boronic acid ligands and second-generation CODs that are derived from 4aminophenylboronic acid. The $\mathrm{EC}_{50}$ of the former was $52 \pm$ $8 \mu \mathrm{g} \mathrm{mL} \mathrm{m}^{-1}$, while the latter showed higher potency with $\mathrm{EC}_{50}$ of $5.2 \pm 0.7 \mu \mathrm{g} \mathrm{mL}^{-1}$ against human coronavirus (229E) infection [142].

Several nanotechnology-based systems have been applied in the field of nanomedicine for the purpose of drug delivery. Examples include polymeric nanoparticles that are synthesized from diverse types of polymers, lipid-solid nanoparticles, liposomes, and surfactant-based nanoparticles such as nanoemulsions [143-146]. The major limitation of the available antiviral therapeutics is the nonspecificity leading to unfavorable cytotoxicity of the host cells [147]. Despite the substantial advances made in the field of nanotechnology-based drug delivery systems, its application for the development of antiviral therapies is still limited.

Unsaturated fatty acids and their related metabolites have been previously formulated using nanotechnology-based strategies for the prevention and treatment of several types of cancers and cardiovascular diseases [103]. Likewise, AA and its associated metabolites could be incorporated into nanotechnology-based drug delivery systems that allow for safer and more efficacious delivery of these lipid molecules to the target cells. Given the urgency and seriousness of the current pandemic as well as the reported antiviral activity of polyunsaturated fatty acids including AA [43], we propose that nanoencapsulation of $\mathrm{AA}$ and its associated metabolites such as 16- and 19-HETE as well as their corresponding synthetic analogs will contribute to the development of novel interventions for the management of COVID-19.

Funding This work was supported by a grant from the Canadian Institutes of Health Research [Grant 168846] to A.O.S.E. S.M.S. is the recipient of the Alberta Innovates Graduate Student Scholarship and the Alberta Graduate Excellence Scholarship. M.A.E. is the recipient of the Antoine Noujaim Graduate Scholarship in Pharmaceutical Sciences.

\section{Compliance with ethical standards}

Conflict of interest The authors declare that they have no conflicts of interest.

\section{References}

1. M.M. Khan, A. Noor, A. Madni, M. Shafiq, Emergence of novel coronavirus and progress toward treatment and vaccine. Rev. Med. Virol. 30, e2116 (2020)

2. COVID-19 Map - Johns Hopkins Coronavirus Resource Center. https://coronavirus.jhu.edu/map.html. Accessed 17 Jun 2020

3. S. Satarker, M. Nampoothiri, Structural Proteins in severe acute respiratory syndrome coronavirus-2. Arch. Med. Res. 51, 482$491(2020)$

4. A. Abeygunasekera, S. Jayasinghe, Is the anti-filarial drug diethylcarbamazine useful to treat COVID-19? Med. Hypotheses 143, 109843 (2020). https://doi.org/10.1016/j.mehy.2020.109843

5. D. Tang, P. Comish, R. Kang, The hallmarks of COVID-19 disease. PLoS Pathog. 16, e1008536 (2020)

6. N. Van Doremalen, T. Bushmaker, D.H. Morris, et al., Aerosol and surface stability of SARS-CoV-2 as compared with SARSCoV-1. N. Engl. J. Med. 382, 1564-1567 (2020)

7. How Coronavirus Spreads | CDC. https://www.cdc.gov/ coronavirus/2019-ncov/prevent-getting-sick/how-covid-spreads. html. Accessed 17 Jun 2020

8. S.A. Lauer, K.H. Grantz, Q. Bi, F.K. Jones, Q. Zheng, H.R. Meredith, A.S. Azman, N.G. Reich, J. Lessler, The incubation period of coronavirus disease 2019 (CoVID-19) from publicly reported confirmed cases: Estimation and application. Ann. Intern. Med. 172, 577-582 (2020). https://doi.org/10.7326/M200504

9. Q. Li, X. Guan, P. Wu, X. Wang, L. Zhou, Y. Tong, R. Ren, K.S.M. Leung, E.H.Y. Lau, J.Y. Wong, X. Xing, N. Xiang, Y. Wu, C. Li, Q. Chen, D. Li, T. Liu, J. Zhao, M. Liu, W. Tu, C. Chen, L. Jin, R. Yang, Q. Wang, S. Zhou, R. Wang, H. Liu, Y. Luo, Y. Liu, G. Shao, H. Li, Z. Tao, Y. Yang, Z. Deng, B. Liu, Z. Ma, Y. Zhang, G. Shi, T.T.Y. Lam, J.T. Wu, G.F. Gao, B.J. Cowling, B. Yang, G.M. Leung, Z. Feng, Early transmission dynamics in Wuhan, China, of novel coronavirus-infected pneumonia. N. Engl. J. Med. 382, 1199-1207 (2020)

10. Z. Wu, J.M. McGoogan, Characteristics of and Important lessons from the coronavirus disease 2019 (COVID-19) outbreak in China: summary of a report of 72314 cases from the Chinese Center for Disease Control and Prevention. JAMA 323, 1239 $1242(2020)$

11. S. Zaim, J.H. Chong, V. Sankaranarayanan, A. Harky, COVID-19 and multiorgan response. Curr. Probl. Cardiol. 45, 100618 (2020)

12. G.A. Farcas, S.M. Poutanen, T. Mazzulli, B.M. Willey, J. Butany, S.L. Asa, P. Faure, P. Akhavan, D.E. Low, K.C. Kain, Fatal severe acute respiratory syndrome is associated with multiorgan 
involvement by coronavirus. J. Infect. Dis. 191, 193-197 (2005). https://doi.org/10.1086/426870

13. T. Wang, Z. Du, F. Zhu, Z. Cao, Y. An, Y. Gao, B. Jiang. Comorbidities and multi-organ injuries in the treatment of COVID-19. Lancet. 395(10228), e52 (2020). https://doi.org/10. 1038/s41423-020-0372-4

14. R.M. Anderson, H. Heesterbeek, D. Klinkenberg, T.D. Hollingsworth, How will country-based mitigation measures influence the course of the COVID-19 epidemic? Lancet 395, 931$934(2020)$

15. F.P. Guengerich, in Chapter 9, Human cytochrome P450 enzymes, ed. by P.R. Ortiz de Montellano. Cytochrome P450: Structure, Mechanism, andBiochemistry, 4th ed (New York: Springer, 2015), p. 523-785.

16. S.M. Shoieb, A.A. El-Sherbeni, A.O.S. El-Kadi, Subterminal hydroxyeicosatetraenoic acids: crucial lipid mediators in normal physiology and disease states. Chem. Biol. Interact. 299, 140-150 (2019)

17. A. Dutta, N. Sharma-Walia, Curbing lipids: impacts ON cancer and viral infection. Int. J. Mol. Sci. 20 (2019)

18. S.M. Shoieb, A.O.S. El-Kadi, S-enantiomer of 19hydroxyeicosatetraenoic acid preferentially protects against angiotensin II-induced cardiac hypertrophy. Drug Metab. Dispos. 46, 1157-1168 (2018). https://doi.org/10.1124/dmd.118.082073

19. A. Dhanasekaran, R. Al-Saghir, B. Lopez, et al., Protective effects of epoxyeicosatrienoic acids on human endothelial cells from the pulmonary and coronary vasculature. Am. J. Physiol. Heart Circ. Physiol. 291, H517-H531 (2006). https://doi.org/10.1152/ ajpheart.00953.2005

20. C. Westphal, A. Konkel, W.H. Schunck, Cytochrome P450 enzymes in the bioactivation of polyunsaturated fatty acids and their role in cardiovascular disease. Adv. Exp. Med. Biol. 851, 151-187 (2015). https://doi.org/10.1007/978-3-319-16009-2_6

21. W.B. Campbell, D. Gebremedhin, P.F. Pratt, D.R. Harder, Identification of epoxyeicosatrienoic acids as endothelium-derived hyperpolarizing factors. Circ. Res. 78, 415-423 (1996). https://doi.org/10.1161/01.RES.78.3.415

22. B. Fissithaler, R. Popp, L. Kiss, et al., Cytochrome P450 2C is an EDHF synthase in coronary arteries. Nature 401, 493-497 (1999). https://doi.org/10.1038/46816

23. L. Wan, Z. Li, T. Liu, X. Chen, Q. Xu, W. Yao, C. Zhang, Y, Zhang, Epoxyeicosatrienoic acids: emerging therapeutic agents for central post-stroke pain. Pharmacol. Res. 159, 104923 (2020)

24. T.R. Harris, B.D. Hammock, Soluble epoxide hydrolase: gene structure, expression and deletion. Gene 526, 61-74 (2013)

25. J.D. Imig, B.D. Hammock, Soluble epoxide hydrolase as a therapeutic target for cardiovascular diseases. Nat. Rev. Drug Discov. 8, 794-805 (2009)

26. L. Vanella, M. Canestraro, C.R. Lee, J. Cao, D.C. Zeldin, M.L. Schwartzman, N.G. Abraham, Soluble epoxide hydrolase null mice exhibit female and male differences in regulation of vascular homeostasis. Prostaglandins Other Lipid Mediat 120, 139-147 (2015). https://doi.org/10.1016/j.prostaglandins.2015.04.004

27. H.C. Shen, Soluble epoxide hydrolase inhibitors: a patent review. Expert Opin. Ther. Pat. 20, 941-956 (2010)

28. V.J. Hammond, V.B. O'Donnell, Esterified eicosanoids: generation, characterization and function. Biochim. Biophys. Acta Biomembr. 1818, 2403-2412 (2012)

29. S. Elkhatali, A.A. El-Sherbeni, O.H. Elshenawy, et al., 19Hydroxyeicosatetraenoic acid and isoniazid protect against angiotensin II-induced cardiac hypertrophy. Toxicol. Appl. Pharmacol. 289, 550-559 (2015). https://doi.org/10.1016/j.taap.2015.10.003

30. R. Dakarapu, R. Errabelli, V.L. Manthati, A.M. Adebesin, D.K. Barma, D. Barma, V. Garcia, F. Zhang, M.L. Schwartzman, J.R. Falck. 19-Hydroxyeicosatetraenoic acid analogs: antagonism of 20-hydroxyeicosatetraenoic acid-induced vascular sensitization and hypertension. Bioorg. Med. Chem. Lett. 29(19), 126616 (2019). https://doi.org/10.1016/j.bmcl.2019.08.020

31. Y.K. Reddy, L.M. Reddy, J.H. Capdevila, J.R. Falck, Practical, asymmetric synthesis of 16-hydroxyeicosa-5(Z),8(Z),11(Z), 14(Z)-tetraenoic acid (16-HETE), an endogenous inhibitor of neutrophil activity. Bioorg. Med. Chem. Lett. 13, 3719-3720 (2003). https://doi.org/10.1016/j.bmcl.2003.08.005

32. RANDOMISED EVALUATION OF COVID-19 THERAPY (RECOVERY)

33. H. Ledford, Coronavirus breakthrough: dexamethasone is first drug shown to save lives. Nature. 582, 469 (2020). https://doi. org/10.1038/d41586-020-01824-5

34. J.M. Sanders, M.L. Monogue, T.Z. Jodlowski, J.B. Cutrell, Pharmacologic treatments for coronavirus disease 2019 (COVID-19): a review. JAMA 323, 1824-1836 (2020)

35. J.F.W. Chan, K.K.W. To, H. Tse, et al., Interspecies transmission and emergence of novel viruses: Lessons from bats and birds. Trends Microbiol. 21, 544-555 (2013)

36. J.F.W. Chan, S.K.P. Lau, P.C.Y. Woo, The emerging novel Middle East respiratory syndrome coronavirus: the "knowns" and "unknowns". J. Formos. Med. Assoc. 112, 372-381 (2013)

37. N. Chazal, D. Gerlier, Virus entry, assembly, budding, and membrane rafts. Microbiol. Mol. Biol. Rev. 67(2), 226-237 (2003). https://doi.org/10.1128/mmbr.67.2.226-237.2003

38. P.D. Nagy, J.R.P.M. Strating, F.J.M. van Kuppeveld, Building viral replication organelles: close encounters of the membrane types. PLoS Pathog. 12, e1005912 (2016)

39. J. Zhang, A. Pekosz, R.A. Lamb, Influenza virus assembly and lipid raft microdomains: a role for the cytoplasmic tails of the spike glycoproteins. J. Virol. 74, $4634-4644$ (2000). https://doi. org/10.1128/jvi.74.10.4634-4644.2000

40. N. Chazal, D. Gerlier. Virus entry, assembly, budding, and membrane rafts. Microbiol. Mol. Biol. Rev. 67(2), 226-237 (2003)

41. E.A. Dennis, J. Cao, Y.H. Hsu, V. Magrioti, G. Kokotos, Phospholipase A2 enzymes: physical structure, biological function, disease implication, chemical inhibition, and therapeutic intervention. Chem. Rev. 111, 6130-6185 (2011)

42. U.N. Das, Can bioactive lipids inactivate coronavirus (COVID19)? Arch. Med. Res. 51, 282-286 (2020). https://doi.org/10. 1016/j.arcmed.2020.03.004

43. U.N. Das, Arachidonic acid and other unsaturated fatty acids and some of their metabolites function as endogenous antimicrobial molecules: A review. J. Adv. Res. 11, 57-66 (2018)

44. L. Qun, Rapid investigation plan of clinical courses and key diagnosis and treatment equipment requirements for the patients of the 2019 Novel Coronavirus Pneumonia (COVID-19). Chin J. Endem. 41, 296 (2020)

45. Smeitink J, Jiang X, Pecheritsyna S, et al (2020) Hypothesis : mPGES-1-derived prostaglandin E2, a so far missing link in COVID-19 pathophysiology ? 1-19. https://doi.org/10.20944/ preprints202004.0180.v1

46. D.R. Nelson, D.C. Zeldin, S.M.G. Hoffman, L.J. Maltais, H.M. Wain, D.W. Nebert, Comparison of cytochrome P450 (CYP) genes from the mouse and human genomes, including nomenclature recommendations for genes, pseudogenes and alternativesplice variants. Pharmacogenetics 14, 1-18 (2004)

47. M. Rosolowsky, W.B. Campbell, Synthesis of hydroxyeicosatetraenoic (HETEs) and epoxyeicosatrienoic acids (EETs) by cultured bovine coronary artery endothelial cells. Biochim Biophys Acta - Lipids Lipid Metab 1299, 267-277 (1996). https://doi.org/10.1016/0005-2760(95)00216-2

48. K. Node, Y. Huo, X. Ruan, et al., Anti-inflammatory properties of cytochrome P450 epoxygenase-derived eicosanoids. Science 285(80), 1276-1279 (1999). https://doi.org/10.1126/science. 285. 5431.1276 
49. D.W. Gilroy, M.L. Edin, R.P.H.D. Maeyer, et al., CYP450-derived oxylipins mediate inflammatory resolution. Proc. Natl. Acad. Sci. U. S. A. 113, E3240-E3249 (2016). https://doi.org/ 10.1073/pnas. 1521453113

50. A. Xu, J. Ma, X. Guo, L. Wang, J. Wu, J. Zhang, Y. Bai, J. Xu, Z. Lu, Z. Xu, X. Zhang, G. Ding, Y. Hong, F. du, Y. Wu, L. Yan, J. Tang, X. Cai, J. Dong, C. Xu, J. Ren, X. Chen, C. Gao, B. Zhang, Q. Yang, R. Moolenaar, Y. Cai, S.L. Jackson, G. Xie, S. Yu, J. Cui, Z. Wang, L. Zhao, L. Ju, D. Shen, S. Yun, X. Liang, Z. Bi, Y. Wang, Association of a Province-wide intervention with salt intake and hypertension in Shandong province, China, 2011-2016. JAMA Intern. Med. 180, 877-886 (2020)

51. Q. Ruan, K. Yang, W. Wang, L. Jiang, J. Song, Correction to: Clinical predictors of mortality due to COVID-19 based on an analysis of data of 150 patients from Wuhan, China (Intensive Care Medicine, (2020), 46, 5, (846-848), 10.1007/s00134-02005991-x). Intensive Care Med. 46, 1294-1297 (2020)

52. F. Zhou, T. Yu, R. Du, et al., Clinical course and risk factors for mortality of adult inpatients with COVID-19 in Wuhan, China: a retrospective cohort study. Lancet 395, 1054-1062 (2020). https:// doi.org/10.1016/S0140-6736(20)30566-3

53. C. Zhang, Z. Wu, J.W. Li, H. Zhao, G.Q. Wang, Cytokine release syndrome in severe COVID-19: interleukin-6 receptor antagonist tocilizumab may be the key to reduce mortality. Int. J. Antimicrob. Agents 55, 105954 (2020). https://doi.org/10.1016/j.ijantimicag. 2020.105954

54. Y. Xiong, Y. Liu, L. Cao, D. Wang, M. Guo, A. Jiang, D. Guo, W. Hu, J. Yang, Z. Tang, H. Wu, Y. Lin, M. Zhang, Q. Zhang, M. Shi, Y. Liu, Y. Zhou, K. Lan, Y. Chen, Transcriptomic characteristics of bronchoalveolar lavage fluid and peripheral blood mononuclear cells in COVID-19 patients. Emerg Microbes Infect 9, 761-770 (2020). https://doi.org/10.1080/22221751.2020. 1747363

55. D. McGonagle, K. Sharif, A. O'Regan, C. Bridgewood, The role of cytokines including interleukin-6 in COVID-19 induced pneumonia and macrophage activation syndrome-like disease. Autoimmun. Rev. 19, 102537 (2020)

56. Potere N, Di Nisio M, Cibelli D, et al (2020) Interleukin-6 receptor blockade with subcutaneous tocilizumab in severe COVID-19 pneumonia and hyperinflammation: a case-control study. Ann Rheum Dis Annrheumdis 2020-218243. https://doi.org/10.1136/ annrheumdis-2020-218243

57. Y. Sano, S. Toyoshima, Y. Miki, Y. Taketomi, M. Ito, H. Lee, S. Saito, M. Murakami, Y. Okayama, Activation of inflammation and resolution pathways of lipid mediators in synovial fluid from patients with severe rheumatoid arthritis compared with severe osteoarthritis. Asia Pac Allergy, 10 (2020). https://doi.org/10. 5415/apallergy.2020.10.e21

58. H. Brouwers, J. Von Hegedus, R. Toes, et al., Lipid mediators of inflammation in rheumatoid arthritis and osteoarthritis. Best Pract. Res. Clin. Rheumatol. 29, 741-755 (2015)

59. C.N. Serhan, S.D. Brain, C.D. Buckley, D.W. Gilroy, C. Haslett, L.A.J. O'Neill, M. Perretti, A.G. Rossi, J.L. Wallace, Resolution of inflammation: state of the art, definitions and terms. FASEB J. 21, 325-332 (2007). https://doi.org/10.1096/fj.06-7227rev

60. C.N. Serhan, A search for endogenous mechanisms of anti-inflammation uncovers novel chemical mediators: missing links to resolution. Histochem. Cell Biol. 122, 305-321 (2004)

61. B.D. Levy, C.B. Clish, B. Schmidt, K. Gronert, C.N. Serhan, Lipid mediator class switching during acute inflammation: signals in resolution. Nat. Immunol. 2, 612-619 (2001). https://doi.org/ $10.1038 / 89759$

62. C.D. Buckley, D.W. Gilroy, C.N. Serhan, Proresolving lipid mediators and mechanisms in the resolution of acute inflammation. Immunity 40, 315-327 (2014)
63. C.N. Serhan, N. Chiang, Endogenous pro-resolving and anti-inflammatory lipid mediators: a new pharmacologic genus. Br. J. Pharmacol. (2008)

64. G.L. Bannenberg, N. Chiang, A. Ariel, M. Arita, E. Tjonahen, K.H. Gotlinger, S. Hong, C.N. Serhan. Molecular circuits of resolution: formation and actions of resolvins and protectins. J. Immunol. 174, 5884c-55884c (2005). https://doi.org/10.4049/ jimmunol.174.9.5884c

65. C. Skarke, N. Alamuddin, J.A. Lawson, X. Li, J.F. Ferguson, M.P. Reilly, G.A. FitzGerald, Bioactive products formed in humans from fish oils. J. Lipid Res. 56, 1808-1820 (2015). https://doi. org/10.1194/jlr.M060392

66. A.E. Barden, V. Chavez, M. Phillips, E. Mas, L.J. Beilin, K.D. Croft, T.A. Mori, I.B. Puddey, A randomized trial of effects of alcohol on cytochrome P450 eicosanoids, mediators of inflammation resolution, and blood pressure in men. Alcohol. Clin. Exp. Res. 41, 1666-1674 (2017). https://doi.org/10.1111/acer.13466

67. Z. Zhou, L. Ren, L. Zhang, J. Zhong, Y. Xiao, Z. Jia, L. Guo, J. Yang, C. Wang, S. Jiang, D. Yang, G. Zhang, H. Li, F. Chen, Y. $\mathrm{Xu}$, M. Chen, Z. Gao, J. Yang, J. Dong, B. Liu, X. Zhang, W. Wang, K. He, Q. Jin, M. Li, J. Wang, Overly exuberant innate immune response to SARS-CoV-2 infection. SSRN Electron. J. (2020). https://doi.org/10.2139/ssrn.3551623

68. B.D. Pence, Severe COVID-19 and aging: are monocytes the key? GeroScience 1 (2020)

69. J. Bystrom, J.A. Wray, M.C. Sugden, M.J. Holness, K.E. Swales, T.D. Warner, M.L. Edin, D.C. Zeldin, D.W. Gilroy, D. BishopBailey, Endogenous epoxygenases are modulators of monocyte/ macrophage activity. PLoS One 6, e26591 (2011). https://doi.org/ 10.1371/journal.pone.0026591

70. U. Hoff, G. Bubalo, M. Fechner, M. Blum, Y. Zhu, A. Pohlmann, J. Hentschel, K. Arakelyan, E. Seeliger, B. Flemming, D. Gürgen, M. Rothe, T. Niendorf, V.L. Manthati, J.R. Falck, M. Haase, W.H. Schunck, D. Dragun, A synthetic epoxyeicosatrienoic acid analogue prevents the initiation of ischemic acute kidney injury. Acta Physiol. 227, e13297 (2019). https://doi.org/10.1111/apha.13297

71. H.H. Sung, H.J. Tsai, J.Y. Liu, et al., Orally bioavailable potent soluble epoxide hydrolase inhibitors. J. Med. Chem. 50, 38253840 (2007). https://doi.org/10.1021/jm070270t

72. N. Tripathi, S. Paliwal, S. Sharma, K. Verma, R. Gururani, A. Tiwari, A. Verma, M. Chauhan, A. Singh, D. Kumar, A. Pant, Discovery of Novel soluble epoxide hydrolase inhibitors as potent vasodilators. Sci. Rep. 8, 14604 (2018). https://doi.org/10.1038/ s41598-018-32449-4

73. Z. Ye, Y. Wang, L.E. Colunga-Lozano, et al., Efficacy and safety of corticosteroids in COVID-19 based on evidence for COVID19 , other coronavirus infections, influenza, community-acquired pneumonia and acute respiratory distress syndrome: a systematic review and meta-analysis. Can. Med. Assoc. J. 192, cmaj.200645 (2020). https://doi.org/10.1503/cmaj.200645

74. WHO welcomes preliminary results about dexamethasone use in treating critically ill COVID-19 patients. https:/www.who.int/ news-room/detail/16-06-2020-who-welcomes-preliminaryresults-about-dexamethasone-use-in-treating-critically-ill-covid19-patients. Accessed 11 Jul 2020

75. J. Grein, N. Ohmagari, D. Shin, G. Diaz, E. Asperges, A. Castagna, T. Feldt, G. Green, M.L. Green, F.X. Lescure, E. Nicastri, R. Oda, K. Yo, E. Quiros-Roldan, A. Studemeister, J. Redinski, S. Ahmed, J. Bernett, D. Chelliah, D. Chen, S. Chihara, S.H. Cohen, J. Cunningham, A. D'Arminio Monforte, S. Ismail, H. Kato, G. Lapadula, E. L'Her, T. Maeno, S. Majumder, M. Massari, M. Mora-Rillo, Y. Mutoh, D. Nguyen, E. Verweij, A. Zoufaly, A.O. Osinusi, A. DeZure, Y. Zhao, L. Zhong, A. Chokkalingam, E. Elboudwarej, L. Telep, L. Timbs, I. Henne, S. Sellers, H. Cao, S.K. Tan, L. Winterbourne, P. Desai, R. Mera, A. Gaggar, R.P. Myers, D.M. Brainard, R. Childs, T. 
Flanigan, Compassionate use of remdesivir for patients with severe Covid-19. N. Engl. J. Med. 382, 2327-2336 (2020). https:// doi.org/10.1056/NEJMoa2007016

76. J. Bellien, R. Joannides, Epoxyeicosatrienoic acid pathway in human health and diseases. J. Cardiovasc. Pharmacol. 61(3), 188196 (2013). https://doi.org/10.1097/FJC.0b013e318273b007

77. L. Wang, G. Luo, L.F. Zhang, H.X. Geng, Neuroprotective effects of epoxyeicosatrienoic acids. Prostaglandins Other Lipid Mediat. 138, 9-14 (2018)

78. P. Sarkar, I. Zaja, M. Bienengraeber, K.R. Rarick, M. Terashvili, S. Canfield, J.R. Falck, D.R. Harder, Epoxyeicosatrienoic acids pretreatment improves amyloid $\beta$-induced mitochondrial dysfunction in cultured rat hippocampal astrocytes. Am. J. Physiol. Heart Circ. Physiol., 306-H484 (2014). https://doi.org/10.1152/ ajpheart.00001.2013

79. D. Panigrahy, M.M. Gilligan, S. Huang, A. Gartung, I. CortésPuch, P.J. Sime, R.P. Phipps, C.N. Serhan, B.D. Hammock, Inflammation resolution: a dual-pronged approach to averting cytokine storms in COVID-19? Cancer Metastasis Rev. 39, 337-340 (2020)

80. I.J. Koralnik, K.L. Tyler, COVID-19: A global threat to the nervous system. Ann. Neurol. 88, 1-11 (2020)

81. A.L. Johnson, K.Z. Edson, R.A. Totah, A.E. Rettie, in Advances in pharmacology. Cytochrome P450 $\omega$-hydroxylases in inflammation and cancer (Academic Press Inc., 2015), pp. 223-262

82. Cytochrome P450: structure, mechanism, and biochemistry Google Books. https://books.google.ca/books?hl=en\&lr=\&id= W5 OPK6tFdYC\&oi=fnd\&pg=PR 19\&dq=Cytochrome+ $\mathrm{P} 450$ \& ots $=$ PUQvtuGB0s\&sig $=5$ brCJ0N72PU $3 \mathrm{qILu} 5 \mathrm{~Eb}-$ xo0KBT $8 \&$ redir esc $=\mathrm{y} \# \mathrm{v}=$ onepage $\& \mathrm{q}=\mathrm{Cy}$ tochromeP450\&f $=$ false. Accessed $1 \overline{1}$ Jul 2020

83. R.M. Laethem, M. Balazy, J.R. Falck, et al., Formation of 19(S)-, 19(R)-, and 18(R)-hydroxyeicosatetraenoic acids by alcohol-inducible cytochrome P450 2E1. J. Biol. Chem. 268, 1291212918 (1993)

84. G.P. Miller, Advances in the interpretation and prediction of CYP2E1 metabolism from a biochemical perspective. Expert Opin. Drug Metab. Toxicol. 4, 1053-1064 (2008)

85. D. Schwarz, P. Kisselev, S.S. Ericksen, G.D. Szklarz, A. Chernogolov, H. Honeck, W.H. Schunck, I. Roots, Arachidonic and eicosapentaenoic acid metabolism by human CYP1A1: highly stereoselective formation of $17(\mathrm{R}), 18(\mathrm{~S})$-epoxyeicosatetraenoic acid. Biochem. Pharmacol. 67, 1445-1457 (2004). https://doi.org/ 10.1016/j.bcp.2003.12.023

86. A.A. El-Sherbeni, A.O.S. El-Kadi, Characterization of arachidonic acid metabolism by rat cytochrome P450 enzymes: the involvement of CYP1As. Drug Metab. Dispos. 42, 1498-1507 (2014). https://doi.org/10.1124/dmd.114.057836

87. A.A. El-Sherbeni, A.O.S. El-Kadi, Repurposing resveratrol and fluconazole to modulate human cytochrome P450-mediated arachidonic acid metabolism. Mol. Pharm. 13, 1278-1288 (2016). https://doi.org/10.1021/acs.molpharmaceut.5b00873

88. K.P. Steinberg, J.A. Milberg, T.R. Martin, R.J. Maunder, B.A. Cockrill, L.D. Hudson, Evolution of bronchoalveolar cell populations in the adult respiratory distress syndrome. Am. J. Respir. Crit. Care Med. 150, 113-122 (1994). https://doi.org/10.1164/ ajrccm.150.1.8025736

89. C. Summers, N.R. Singh, J.F. White, I.M. Mackenzie, A. Johnston, C. Solanki, K.K. Balan, A.M. Peters, E.R. Chilvers, Pulmonary retention of primed neutrophils: a novel protective host response, which is impaired in the acute respiratory distress syndrome. Thorax 69, 623-629 (2014). https://doi.org/10.1136/ thoraxjnl-2013-204742

90. G.S. Worthen, B. Schwab, E.L. Elson, G.P. Downey, Mechanics of stimulated neutrophils: cell stiffening induces retention in capillaries. Science 245(80), 183-186 (1989). https://doi.org/10. $1126 /$ science. 2749255

91. L.A. Smedly, M.G. Tonnesen, R.A. Sandhaus, C. Haslett, L.A. Guthrie, R.B. Johnston Jr., P.M. Henson, G.S. Worthen, Neutrophil-mediated injury to endothelial cells. Enhancement by endotoxin and essential role of neutrophil elastase. J. Clin. Invest. 77, 1233-1243 (1986). https://doi.org/10.1172/JCI112426

92. R.H. Simon, P.D. DeHart, R.F. Todd, Neutrophil-induced injury of rat pulmonary alveolar epithelial cells. J. Clin. Invest. 78, 13751386 (1986). https://doi.org/10.1172/JCI1 12724

93. K.P.M. van Kesse, J. Bestebroer, J.A.G. van Strijp, Neutrophilmediated phagocytosis of Staphylococcus aureus. Front. Immunol. 5, 467 (2014). https://doi.org/10.3389/fimmu.2014. 00467

94. M.A. Matthay, L.B. Ware, G.A. Zimmerman, The acute respiratory distress syndrome. J. Clin. Invest. 122, 2731-2740 (2012)

95. H.G. Folkesson, M.A. Matthay, C.A. Hebert, V.C. Broaddus, Acid aspiration-induced lung injury in rabbits is mediated by interleukin- 8-dependent mechanisms. J. Clin. Invest. 96, 107-116 (1995). https://doi.org/10.1172/JCI1 18009

96. M. Bosmann, J.J. Grailer, R. Ruemmler, N.F. Russkamp, F.S. Zetoune, J.V. Sarma, T.J. Standiford, P.A. Ward, Extracellular histones are essential effectors of C5aR- and C5L2-mediated tissue damage and inflammation in acute lung injury. FASEB J. 27(12), 5010-5021 (2013). https://doi.org/10.1096/fj.13-236380

97. P. Borgeat, B. Samuelsson, Arachidonic acid metabolism in polymorphonuclear leukocytes: effects of ionophore A23187. Proc. Natl. Acad. Sci. U. S. A. 76(5), 2148-2152 (1979). https://doi. org/10.1073/pnas.76.5.2148

98. M.M. Bednar, C.E. Gross, M.K. Balazy, Y. Belosludtsev, D.T. Colella, J.R. Falck, M. Balazy, 16(R)-hydroxy-5,8,11,14eicosatetraenoic acid, a new arachidonate metabolite in human polymorphonuclear leukocytes. Biochem. Pharmacol. 60, 447455 (2000). https://doi.org/10.1016/S0006-2952(00)00345-2

99. M.M. Bednar, C.E. Gross, S.R. Russell, S.P. Fuller, T.P. Ahern, D.B. Howard, J.R. Falck, K.M. Reddy, M. Balazy, 16(R)Hydroxyeicosatetraenoic acid, a novel cytochrome P450 Product of arachidonic acid, suppresses activation of human polymorphonuclear leukocytes and reduces intracranial pressure in a rabbit model of thromboembolic stroke. Neurosurgery 47, 1410-1419 (2000). https://doi.org/10.1097/00006123-200012000-00029

100. P.M. Potey, A.G. Rossi, C.D. Lucas, D.A. Dorward, Neutrophils in the initiation and resolution of acute pulmonary inflammation: understanding biological function and therapeutic potential. J. Pathol. 247, 672-685 (2019). https://doi.org/10.1002/path.5221

101. S.M. Shoieb, A.A. El-Sherbeni, A.O.S. El-Kadi, Identification of 19-(S/R)hydroxyeicosatetraenoic acid as the first endogenous noncompetitive inhibitor of cytochrome P450 1B1 with enantioselective activity. Drug Metab. Dispos. 47, 67-70 (2019). https://doi.org/10.1124/dmd.118.084657

102. Lockhart Wolf HC, Sacks G (2002) Methods and products relating to 16-HETE analogs

103. S. Serini, R. Cassano, S. Trombino, G. Calviello, Nanomedicinebased formulations containing $\omega-3$ polyunsaturated fatty acids: potential application in cardiovascular and neoplastic diseases. Int. J. Nanomedicine 14, 2809-2828 (2019). https://doi.org/10. 2147/IJN.S197499

104. X. Chen, Isozyme-specific induction of low-dose aspirin on cytochrome P450 in healthy subjects. Clin. Pharmacol. Ther. 73, 264 271 (2003). https://doi.org/10.1067/mcp.2003.14

105. H.N. Althurwi, O.H. Elshenawy, A.O.S. El-Kadi, Fenofibrate modulates cytochrome P450 and arachidonic acid metabolism in the heart and protects against isoproterenol-induced cardiac hypertrophy. J. Cardiovasc. Pharmacol. 63, 167-177 (2014). https://doi. org/10.1097/FJC.0000000000000036 
106. A.H. Alammari, S.M. Shoieb, Z.H. Maayah, A.O.S. El-Kadi, Fluconazole represses cytochrome P450 1B1 and Its associated arachidonic acid metabolites in the heart and protects against angiotensin II-Induced cardiac hypertrophy. J. Pharm. Sci. 109 (2020). https://doi.org/10.1016/j.xphs.2020.03.016

107. S.M. Shoieb, A.O.S. El-Kadi, Resveratrol attenuates angiotensin II-induced cellular hypertrophy through the inhibition of CYP1B1 and the cardiotoxic mid-chain HETE metabolites. Mol. Cell. Biochem. 471, 165-176 (2020). https://doi.org/10.1007/s11010020-03777-9

108. Z.H. Maayah, J. Levasseur, R. Siva Piragasam, et al., 2Methoxyestradiol protects against pressure overload-induced left ventricular hypertrophy. Sci. Rep. 8 (2018). https://doi.org/10. 1038/s41598-018-20613-9

109. Morgan D'C, Wolf A, Sacks G\& (2003) Methods and products related to 16-HETE analogs

110. A.W. Dreisbach, S.V. Smith, P.B. Kyle, M. Ramaiah, M. Amenuke, M.R. Garrett, S.T. Lirette, M.E. Griswold, R.J. Roman, Urinary CYP eicosanoid excretion correlates with glomerular filtration in African-Americans with chronic kidney disease. Prostaglandins Other Lipid Mediat 113-115, 45-51 (2014). https://doi.org/10.1016/j.prostaglandins.2014.08.002

111. S. Elkhatali, Z.H. Maayah, A.A. El-Sherbeni, et al., Inhibition of mid-chain HETEs Protects against angiotensin II-induced cardiac hypertrophy. J. Cardiovasc. Pharmacol., 70-24 (2017). https://doi. org/10.1097/FJC.0000000000000494

112. E.H. Oliw, J.A. Lawson, A.R. Brash, J.A. Oates, Arachidonic acid metabolism in rabbit renal cortex. Formation of two novel dihydroxyeicosatrienoic acids. J. Biol. Chem. 256, 9924-9931 (1981)

113. N.H.A. Ellah, H.M. Tawfeek, J. John, H.F. Hetta, Nanomedicine as a future therapeutic approach for hepatitis $\mathrm{C}$ virus. Nanomedicine 14, 1471-1491 (2019)

114. N.H. Abd Ellah, S.F. Gad, K. Muhammad, G. E Batiha, H.F. Hetta, Nanomedicine as a promising approach for diagnosis, treatment and prophylaxis against COVID-19. Nanomedicine. 15, 2085-2102 (2020). https://doi.org/10.2217/nnm-2020-0247

115. C. Herzog, K. Hartmann, V. Künzi, O. Kürsteiner, R. Mischler, H. Lazar, R. Glück, Eleven years of Inflexal® V-a virosomal adjuvanted influenza vaccine. Vaccine 27, 4381-4387 (2009)

116. S.N.S. Alconcel, A.S. Baas, H.D. Maynard, FDA-approved poly(ethylene glycol)-protein conjugate drugs. Polym. Chem. 2, 14421448 (2011)

117. B. Rodriguez, D.M. Asmuth, R.M. Matining, J. Spritzler, J.M. Jacobson, R.B. Mailliard, X.D. Li, A.I. Martinez, A.R. Tenorio, F. Lori, J. Lisziewicz, S. Yesmin, C.R. Rinaldo, R.B. Pollard, Safety, tolerability, and immunogenicity of repeated doses of dermavir, a candidate therapeutic HIV vaccine, in HIV-infected patients receiving combination antiretroviral therapy: results of the ACTG 5176 trial. J. Acquir. Immune Defic. Syndr. 64, 351-359 (2013). https://doi.org/10.1097/QAI.0b013e3182a99590

118. B.E. Gilbert, N. Patel, H. Lu, Y. Liu, M. Guebre-Xabier, P.A. Piedra, G. Glenn, L. Ellingsworth, G. Smith, Respiratory syncytial virus fusion nanoparticle vaccine immune responses target multiple neutralizing epitopes that contribute to protection against wildtype and palivizumab-resistant mutant virus challenge. Vaccine 36(52), 8069-8078 (2018). https://doi.org/10.1016/j.vaccine. 2018.10.073

119. Socio-economic impact of COVID-19 | UNDP. https://www. undp.org/content/undp/en/home/coronavirus/socio-economicimpact-of-covid-19.html. Accessed 19 Aug 2020

120. S.E. Cosgrove, The relationship between antimicrobial resistance and patient outcomes: mortality, length of hospital stay, and health care costs. Clin. Infect. Dis. 42(Suppl 2), S82-S89 (2006)
121. M. Qasim, D.J. Lim, H. Park, D. Na, Nanotechnology for diagnosis and treatment of infectious diseases. J. Nanosci. Nanotechnol. 14, 7374-7387 (2014)

122. R. Parboosing, G.E.M. Maguire, P. Govender, H.G. Kruger, Nanotechnology and the treatment of HIV infection. Viruses $\mathbf{4}$, $488-520(2012)$

123. A. Kumar, H. Ma, X. Zhang, K. Huang, S. Jin, J. Liu, T. Wei, W. Cao, G. Zou, X.J. Liang, Gold nanoparticles functionalized with therapeutic and targeted peptides for cancer treatment. Biomaterials 33, 1180-1189 (2012). https://doi.org/10.1016/j. biomaterials.2011.10.058

124. S.E. McNeil, Unique benefits of nanotechnology to drug delivery and diagnostics. Methods Mol. Biol. 697, 3-8 (2011). https://doi. org/10.1007/978-1-60327-198-1_1

125. M.E. Davis, Z. Chen, D.M. Shin, Nanoparticle therapeutics: an emerging treatment modality for cancer. Nat. Rev. Drug Discov. 7, 771-782 (2008)

126. L. Zhang, F.X. Gu, J.M. Chan, A.Z. Wang, R.S. Langer, O.C. Farokhzad, Nanoparticles in medicine: therapeutic applications and developments. Clin. Pharmacol. Ther. 83, 761-769 (2008)

127. P. Orłowski, A. Kowalczyk, E. Tomaszewska, K. RanoszekSoliwoda, A. Węgrzyn, J. Grzesiak, G. Celichowski, J. Grobelny, K. Eriksson, M. Krzyzowska, Antiviral activity of tannic acid modified silver nanoparticles: potential to activate immune response in herpes genitalis. Viruses, 10 (2018). https:// doi.org/10.3390/v10100524

128. L. Lu, R.W.Y. Sun, R. Chen, et al., Silver nanoparticles inhibit hepatitis B virus replication. Antivir. Ther. 13, 252-262 (2008)

129. M.A. Meléndez-Villanueva, K. Morán-Santibañez, J.J. MartínezSanmiguel, R. Rangel-López, M.A. Garza-Navarro, C. Rodríguez-Padilla, D.G. Zarate-Triviño, L.M. Trejo-Ávila, Virucidal activity of gold nanoparticles synthesized by green chemistry using garlic extract. Viruses, 11 (2019). https://doi. org/10.3390/v11121111

130. D.A. Chiappetta, G. Facorro, E. Rubin de Celis, A. Sosnik, Synergistic encapsulation of the anti-HIV agent efavirenz within mixed poloxamine/poloxamer polymeric micelles. Nanomed. Nanotechnol. Biol. Med. 7, 624-637 (2011). https://doi.org/10. 1016/j.nano.2011.01.017

131. M.J. Santos-Martinez, K. Rahme, J.J. Corbalan, C. Faulkner, J.D. Holmes, L. Tajber, C. Medina, M.W. Radomski, Pegylation increases platelet biocompatibility of gold nanoparticles. J. Biomed. Nanotechnol. 10, 1004-1015 (2014). https://doi.org/10.1166/jbn. 2014.1813

132. M.S. Muthu, S. Singh, Targeted nanomedicines: effective treatment modalities for cancer, AIDS and brain disorders. Nanomedicine 4, 105-118 (2009)

133. W.H. De Jong, P.J.A. Borm, Drug delivery and nanoparticles: applications and hazards. Int. J. Nanomedicine 3, 133-149 (2008)

134. H.H. Gustafson, D. Holt-Casper, D.W. Grainger, H. Ghandehari, Nanoparticle uptake: the phagocyte problem. Nano Today 10, 487-510 (2015)

135. E.C. Wang, A.Z. Wang, Nanoparticles and their applications in cell and molecular biology. Integr. Biol. (United Kingdom) 6, 9 26 (2014)

136. M. Hoffmann, H. Kleine-Weber, S. Schroeder, et al., SARS-CoV2 Cell entry depends on ACE2 and TMPRSS2 and is blocked by a clinically proven protease inhibitor. Cell 181, 271-280.e8 (2020). https://doi.org/10.1016/j.cell.2020.02.052

137. F. Li, W. Li, M. Farzan, S.C. Harrison, Structural biology: structure of SARS coronavirus spike receptor-binding domain complexed with receptor. Science 309(5742):1864-1868 (2005). https://doi.org/10.1126/science. 1116480

138. W. Li, C. Zhang, J. Sui, J.H. Kuhn, M.J. Moore, S. Luo, S.K. Wong, I.C. Huang, K. Xu, N. Vasilieva, A. Murakami, Y. He, W.A. Marasco, Y. Guan, H. Choe, M. Farzan, Receptor and viral 
determinants of SARS-coronavirus adaptation to human ACE2. EMBO J. 24, 1634-1643 (2005). https://doi.org/10.1038/sj. emboj.7600640

139. X. Huang, M. Li, Y. Xu, J. Zhang, X. Meng, X. An, L. Sun, L. Guo, X. Shan, J. Ge, J. Chen, Y. Luo, H. Wu, Y. Zhang, Q. Jiang, $\mathrm{X}$. Ning, Novel gold nanorod-based HR1 peptide inhibitor for Middle East respiratory syndrome coronavirus. ACS Appl. Mater. Interfaces 11, 19799-19807 (2019). https://doi.org/10. 1021/acsami.9b04240

140. S. Gierer, S. Bertram, F. Kaup, F. Wrensch, A. Heurich, A. Kramer-Kuhl, K. Welsch, M. Winkler, B. Meyer, C. Drosten, U. Dittmer, T. von Hahn, G. Simmons, H. Hofmann, S. Pohlmann, The Spike protein of the emerging betacoronavirus EMC uses a novel coronavirus receptor for entry, can be activated by TMPRSS2, and is targeted by neutralizing antibodies. J. Virol. 87, 5502-5511 (2013). https://doi.org/10.1128/jvi.00128-13

141. Y. Han, P. Král, Computational design of ACE2-based peptide inhibitors of SARS-CoV-2. ACS Nano 14(14), 5143-5147 (2020). https://doi.org/10.1021/acsnano.0c02857

142. A. Łoczechin, K. Séron, A. Barras, E. Giovanelli, S. Belouzard, Y.T. Chen, N. Metzler-Nolte, R. Boukherroub, J. Dubuisson, S. Szunerits, Functional carbon quantum dots as medical countermeasures to human coronavirus. ACS Appl. Mater. Interfaces
11, 42964-42974 (2019). https://doi.org/10.1021/acsami. $9 \mathrm{~b} 15032$

143. G. Orive, A.R. Gascón, R.M. Hernández, A. Domínguez-Gil, J.L. Pedraz, Techniques: new approaches to the delivery of biopharmaceuticals. Trends Pharmacol. Sci. 25, 382-387 (2004)

144. F.H.W. Shand, S.Y. Langenbach, C.R. Keenan, S.P. Ma, B.J. Wheaton, M.J. Schuliga, J. Ziogas, A.G. Stewart, In vitro and in vivo evidence for anti-inflammatory properties of 2methoxyestradiol. J. Pharmacol. Exp. Ther. 336, 962-972 (2011). https://doi.org/10.1124/jpet.110.174854

145. J.K. Patra, G. Das, L.F. Fraceto, et al., Nano based drug delivery systems: recent developments and future prospects 10 Technology 1007 Nanotechnology 03 Chemical Sciences 0306 Physical Chemistry (incl. Structural) 03 Chemical Sciences 0303 Macromolecular and Materials Chemistry 11 Medical and Health Sciences 1115 Pharmacology and Pharmaceutical Sciences 09 Engineering 0903 Biomedical Engineering Prof Ueli Aebi, Prof Peter Gehr. J. Nanobiotechnol. 16, 71 (2018)

146. Z. Liu, S. Tabakman, K. Welsher, H. Dai, Carbon nanotubes in biology and medicine: in vitro and in vivo detection, imaging and drug delivery. Nano Res. 2, 85-120 (2009). https://doi.org/10. 1007/s12274-009-9009-8

147. E. Paintsil, Y.C. Cheng, in Encyclopedia of microbiology. Antiviral agents (Elsevier Inc., 2009), pp. 223-257 